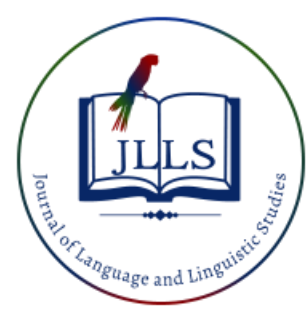

Available online at www.jlls.org

JOURNAL OF LANGUAGE AND LINGUISTIC STUDIES

ISSN: 1305-578X

Journal of Language and Linguistic Studies, 16(3), 1203-1218; 2020

\title{
The application of syntactic parsing strategies during real-time L2 sentence comprehension: Evidence from eye-movement recordings
}

\author{
Onur Uludağ a 1 iD \\ APA Citation: \\ ${ }^{a}$ Yildiz Technical University, Istanbul, Turkey \\ Uludag, O. (2020). The application of syntactic parsing strategies during real-time L2 sentence comprehension: Evidence from eye-movement \\ recordings. Journal of Language and Linguistic Studies, 16(3), 1203-1218 \\ Submission Date:09/03/2020 \\ Acceptance Date:30/06/2020
}

\begin{abstract}
The study aims to investigate whether second language learners perform sentence processing based on syntactic or structure-based parsing strategies during real-time comprehension of constructions with syntactic ambiguities. To this end, the recordings of eye movements from Turkish learners of English and native English speakers as a control group are examined on temporarily ambiguous constructions including relative clause attachment ambiguities. The results indicate that processing decisions in first and second language are systematically driven by structure-based parsing strategies rather than being made randomly with an overreliance on semantic, pragmatic or other types of nonstructural information sources. These findings suggest that L2 learners are indeed capable of constructing and depending on abstract, hierarchically deep and detailed syntactic representations similar to those of native English speakers during the processing of sentences in real time.
\end{abstract}

(c) 2020 JLLS and the Authors - Published by JLLS.

Keywords: sentence processing; parsing; ambiguity resolution; eye-tracking; attachment

\section{Introduction}

Achieving a certain level of mastery in a second language (L2) is surely a challenging task for many, particularly when engagement with the task of language learning takes place at later stages in life. Nevertheless, it is not impossible to attain satisfactory levels of proficiency in an L2 during adulthood and even to display a native-like conduct of the language in some instances with the increasing competency. A plethora of research on adult L2 acquisition has been motivated by the concern to investigate what learners come to know about the mental representation of the grammar to the target language (i.e., abstract linguistic knowledge of L2 learners) and several models have been proposed to explain how this knowledge is attained and put to use (see VanPatten \& Williams, 2007 for a survey of the theoretical models). More recently, there has been a growing interest to examine whether or not the abstract linguistic knowledge of L2 learners is reflected during processing or more specifically parsing of the L2 input in real time (i.e., moment-by-moment syntactic computations performed by L2 learners

\footnotetext{
${ }^{1}$ Corresponding author. Tel.: +0-212-383-4915

E-mail address: ouludag@yildiz.edu.tr
} 
during real-time comprehension of grammatical sentences). What is of interest to the scholars investigating this issue is to offer insights into the relationship between syntax or grammatical knowledge and real-time parsing of L2 input. Examinations on the L2 parsing are essential as learning L2 entails not only the acquisition of knowledge but also the ability to use it in real time and it is argued that possessing necessary linguistic knowledge in place does not guarantee successful parsing in L2 (VanPatten \& Jegerski, 2010, p.8). In this line of investigations on the nature of L2 sentence processing, the methods employed including on-line and off-line measures (see Roberts, 2010 for a discussion) and the types of constructions investigated as stimulus test sentences have been adopted from monolingual (L1) processing research, yet majority of the investigations within this context are driven by basic inquiries from the field of L2 acquisition research, spanning on subjects such as how L2 learners process the target language when compared to native speakers, whether L1 have an effect on L2 learners' parsing decisions in real time, and finally what role the individual differences such as the level of proficiency, the type of immersion and the onset of exposure, etc. have to play (Felser \& Roberts, 2007).

In order to address these questions, research on L2 processing and parsing has focused on the way L2 learners deal with the ambiguous input. The study of ambiguities entails investigating parsing decisions at regions in a sentence where a syntactic preference has to be made by reader/listener to draw a certain structural interpretation among other options. Ambiguity resolution in sentence processing has been studied extensively and different varieties of ambiguous constructions (e.g., relative clause attachment ambiguities, main verb/reduced relative clause ambiguities, prepositional phrase attachment ambiguities, subject/object ambiguities, to name a few) have been focal to these investigations (see Papadopoulou, 2006 for an overview). Similarly, the present study attempts to examine real-time processing of relative clause (RC) attachment ambiguities to test whether $\mathrm{L} 2$ learners are able to perform sentence processing based on structure-based parsing strategies during the interpretation of the sentencelevel L2 input. The following section will provide a background of the considerations under scrutiny before focusing on the empirical design and findings of the experiments.

\subsection{Literature review}

Resolution of syntactic ambiguities has always been a mainstream testing ground because of the cross-linguistic variations in the way the stimulus test sentences are processed differently by speakers of different languages. A typical sample of the type of construction could be demonstrated in the globally ambiguous sentence, Somebody hit the father of the author who was at the café. In this sentence, the $\mathrm{RC}$, who was at the café, could modify either noun phrase (NP), the father or the author. Examples of this sort of modifier attachment ambiguities suggest that when faced with a local ambiguity, the parsing mechanism tends to conform to a particular structural analysis, even if that particular analysis turns out to be incorrect. The empirical evidence indicates that there exists a remarkable consistency regarding the processing decisions of different groups of people from a variety of language backgrounds across different kinds of stimulus test sentences. For instance, it is reported that while native speakers of English, Norwegian, Romanian and Swedish were found to prefer to attach the RC to the second noun, $\mathrm{NP}_{2}$ (the author) in above example, also commonly referred to as low attachment preference, native speakers of German, Dutch, Russian, Spanish, Brazilian and European Portuguese, Japanese and Greek showed a tendency to attach the $\mathrm{RC}$ to the first noun, $\mathrm{NP}_{1}$ (the father), similarly referred to as high attachment preference (see VanPatten \& Jegerski, 2010, p.9 for the references). As for the resolution of the RC ambiguities in Turkish, Kirkici (2004) and Dinctopal-Deniz (2010) indicated that native speakers of Turkish displayed a low attachment preference with a tendency to attach the RC to the $\mathrm{NP}_{2}$.

The cross-linguistic differences in findings suggest that the preference as to which analysis to pursue in ambiguous sentences is not arbitrary and therefore examining such examples has the potential to present us implications about the general makeup of the human sentence parsing mechanism, thus 
researchers seeking to account for these difference have devised a range of models on L1 sentence processing (e.g. the Construal Hypothesis (Frazier \& Clifton, 1996); Recency and Predicate Proximity (Gibson, Pearlmutter, Canseco-Gonzalez \& Hickok, 1996), the Tuning Hypothesis (Brysbaert \&Mitchell, 1996), Modifier Straddling Strategy (Cuetos, Mitchell \& Corley,1996), among others).

As far as sentence processing in L2 is concerned, Clahsen and Felser (2006a, 2006b, 2006c, 2017) formulated a rather famous account known as the Shallow Structure Hypothesis (SSH). It was originally suggested to account for the differences between L1 and L2 in sentence processing. The central assertion of the SSH, which was also refined in a more recent commentary by the researchers (Clahsen \& Felser, 2017), was that irrespective of their proficiency level, L2 learners tend to experience problems when creating and utilizing abstract syntactic representations in real-time comprehension and compared to native speakers, L2 learners are guided more strongly by semantic, pragmatic, plausibility or surface level information. Clahsen and Felser (2006a, 2006b) originally argued that L2 learners could make use of lexical, pragmatic and world knowledge in a native-like manner to construct a semantic representation of a sentence, but that the syntactic representations formed by L2 learners to interpret L2 input data are shallower and less detailed than those of native speakers. Put it differently; while processing target language, L2 learners "underuse" syntactic information and they do not rely on syntactic or structurallydriven parsing strategies to the same extent as native speakers.

Evidence in line with the argument that L2 processing system may rely more predominantly on nongrammatical than grammatical information has been suggested by the studies conducted on the processing of constructions including $\mathrm{RC}$ attachment ambiguities in L2. In fact, RC attachment ambiguity resolution in $\mathrm{L} 2$ has been investigated within two different strands, one aiming to examine bilingual processing with respect to L1/L2 dominance or dependency (e.g. Dussias, 2003; FrenckMestre, 1999, 2002; Fernandez, 2002, 2003), the other focusing on the discussion of whether L2 processing system relies more heavily on nongrammatical than grammatical information (e.g. Felser, Roberts, Marinis \& Gross, 2003; Papadopoulou \& Clahsen, 2003). The studies in the latter line of research is of concern for the present study as they are addressed within the scope of the SSH and form the foundation of the argument that the processing decisions of L2 learners are not guided by syntactic or structure-based parsing strategies which have been demonstrated to play a role in L1 sentence processing.

With regard to the discussion of the syntactic parsing strategies, a prominent proposal offered by Gibson and colleagues (Gibson et al., 1996), is of particular interest to the present study as it has been frequently cited in the investigations that has favored the SSH (e.g. Felser et al., 2003; Papadopoulou \& Clahsen, 2003 among others). According to this proposal, the parsing decisions are determined as a result of the competition between two structure-based parsing principles, namely, Recency and Predicate Proximity. Recency principle, similar to Frazier's late closure (Frazier, 1979) demands new constituents of a sentence to be attached to the most recently constructed structures, hence the low attachment preference illustrated above. It is considered to be the consequence of the general makeup of the human language processor and therefore this principle is unlikely to vary cross-linguistically. On the other hand, Predicate Proximity, which demands the attachment of the constituents to the head of the predicate phrase as close as possible, is language-specific (parameterized). This implies that based on the average distance between a verb and its arguments in a sentence, the relative strength of Predicate Proximity strategy varies cross-linguistically. This principle is frequently addressed in the relevant literature to arguably rationalize the high attachment preference reported in certain languages. Within the framework of the SSH, however, it is hypothesized that L2 learners might fail to apply structure-based processing strategies highlighted above as sufficiently detailed hierarchical representations must be available in the first place for the processing mechanism to make any structure-based attachment preferences (Clahsen $\&$ Felser, 2006a, p.113) and this sort of representations might not be computed or generated during real- 
time interpretation of L2 sentences. Therefore, lexico-semantic, pragmatic, or other sorts of nongrammatical information could be prioritized in L2 processing (Clahsen \& Felser, 2017, p. 3) and when there is no such information available to guide the parsing decisions of L2 learners, the RC attachment preferences are randomly made (Clahsen \& Felser, 2006b, p.18) without displaying a consistent attachment decision in either direction.

Evidence supporting the claims of the SHH was offered by Felser et al., 2003. The researchers investigated RC attachment preferences on sentence types such as the following: The dean liked the secretary of/with the professors who was/were reading. The $\mathrm{RC}$ who was/were reading is sequenced in a structural position that makes it possible to modify either high NP (the secretary) or the low NP (the professors) and it is the subject-verb agreement (number information) that enables the resolution of the ambiguity (i.e., high attachment forced by was towards the NP the secretary and low attachment forced by were towards the NP the professors). The researchers tested proficient Greek L1 - English L2 and German L1 - English L2 learners on different variations of the above example. Both groups of learners showed a clear low attachment preference demonstrated by the faster reading times in the self-paced reading task when the preposition with (the professor with the secretary) was used to connect the constituents of the complex NP. On the other hand, no attachment preference was reported when the preposition of (the secretary of the professor) was employed in the complex NP. The researchers noted that while L2 participants did manage to utilize lexical/semantic information which was assumed to be provided with the preposition with, they did not show any indication of the use of Predicate Proximity which is the structure-based processing principle evidenced to be functional in parsing decisions of L1 German and Greek speakers for similar constructions. Interestingly enough, both groups also failed to show similar attachment preferences to the native-like processing of these structures (low attachment preference in English) in accordance with the Recency principle.

In another study investigating whether German, Russian and Spanish learners of L2 Greek showed similar processing decisions to those of Greek native speakers in their interpretation of RC structures, Papadopoulou and Clahsen (2003) got comparably similar results to those of Felser et al. (2003). More specifically, L1 Greek speakers displayed a high attachment preference when the preposition of (the secretary of the professor) was used to connect the constituents of the complex genitive NPs whereas they had a low attachment preference in the NPs constructions connected with the preposition with. On the other hand, learners of L2 Greek, irrespective of their first language, displayed no statistically significant attachment preference in the constructions including complex genitive NPs (i.e. the secretary of the professor), while showing low attachment preference in the NP structures with the preposition with. Basing on their set of findings, the researchers argued that lexical/semantic information drive processing decisions of L2 learners.

In a more recent investigation, which also motivated the present study, Dinctopal-Deniz (2010) examined the processing of the RC attachment preferences of Turkish learners of L2 English compared to native speakers of English through an off-line paper-and-pencil comprehension test and on-line selfpaced reading tasks. The test sentences included both globally ambiguous RC constructions and temporarily ambiguous ones that were manipulated using animacy information in the complex genitive $\mathrm{NP}$ and in the disambiguating region. The results demonstrated that in both on-line and off-line tasks, the native speakers of English showed low attachment preference. However, Turkish learners of L2 English did not show processing behaviors similar to native English speakers. While they indicated a high attachment preference when the NPs were animate, they did not seem to present statistically significant attachment preference when the NPs were inanimate. On the other hand, in the off-line comprehension test they preferred to attach the RC to a high NP irrespective of the animacy information that the NPs carried. In her discussion of the results, Dinctopal-Deniz (2010) maintained that the data from the Turkish learners of L2 English indicating no attachment preference in the absence of lexical 
information during on-line processing was congruent with the predictions of SSH concerning shallow L2 processing.

Of interest to the present study is a new strand of research that has failed to find support for the suggestions of SSH. In their study, Witzel, Witzel and Nicol (2012) set out to investigate the processing of three types of temporarily ambiguous English sentences including RC attachment ambiguity resolution by Chinese speakers of L2 English. Using an eye-tracking methodology, which the researchers claimed to be more sensitive to reveal consistent results regarding L2 processing decisions of learners than a self-paced reading methodology, the researchers noted that their findings presented a challenge to the assertions of SSH. Specifically, the results of Witzel et al. (2012) disputed the proposition that L2 sentence comprehension is featured with shallow structural processing as the experimental group displayed the application of structure-based parsing strategies during comprehension of specific structural configurations employed in the study. This suggests that L2 learners are indeed capable of performing structure-based processing that is sufficiently deep and detailed enough to be functioning during real-time L2 sentence comprehension.

The difference in the outcomes between the studies that have lend support to the SSH and Witzel et al. (2012) renders generalizability of the basic tenets of SSH problematic and therefore creates the need for further investigations to see whether or not the new results will pattern like SSH-supporting studies or whether they will pattern like those of Witzel et al. (2012), or whether they will show a pattern in some different way.

\subsection{Research questions}

The present study aims to further investigate whether L2 learners perform sentence processing based on syntactic or structurally-driven parsing strategies during real-time comprehension of constructions with syntactic ambiguities. With this purpose in mind, the eye movements of Turkish learners of L2 English and native English speakers as a control group were examined on sentence types including temporarily ambiguous RC constructions. The research questions addressed in the present study are as follows:

1. Do the processing decisions of Turkish learners of L2 English differ from those of native English speakers during real-time comprehension of temporarily ambiguous statements including English RC constructions?

2. Do Turkish learners of L2 English make use of syntactic information in their resolution of temporarily ambiguous statements including English RC constructions?

\section{Method}

The present study employed an eye-tracking methodology, details of which provided below, to enhance the possibility of revealing the application of processing strategies during real-time comprehension of test sentences because even for the studies examining L1 RC attachment preferences in the relevant literature, differences of reading times between low versus high $\mathrm{RC}$ attachment strategies are often subtle and eye-tracking methodology appears to reveal those differences more consistently than self-paced reading (Carreiras \& Clifton, 1999).

\subsection{Participants}

The participants included Turkish learners of L2 English in the experimental group and a control group consisting of native English speakers. Those employed in the experimental group were all students 
majoring in English-medium instruction (EMI) programs at a public university in Turkey and they ranged in age from 19 to 22 . Before the study was conducted, all students had received a formal language instruction by attending a preparatory program and studied English intensively for a year. The participants' level of proficiency in English had been assessed at the end of the preparatory program by an in-house proficiency exam which was a conceptual equivalent of Cambridge First Certificate Exam in terms of the content and the difficulty level. Having successfully passed the proficiency test, they were enrolled in their EMI major programs and also had to take a B2-level English class during the first semester of their disciplinary education in their own departments.

The control group consisted of native English speakers who were living in Turkey at the time of the experimentation. They were all graduates of a university with a mean age of 36 and they were comparable to the Turkish participants with regard to their cognitive abilities and socio-linguistic background.

All subjects participated in the experiment on a voluntary basis and gave a written informed consent. The final number of participants were fifty, distributed as follows: L2 English learner group $(n=26)$ and control group $(n=24)$.

\subsection{Instruments}

Reflexive pronouns with gender information (himself/herself) and their agreement with the antecedent were manipulated as a disambiguating cue to resolve the temporary $\mathrm{RC}$ attachment ambiguity as previous research has indicated that $\mathrm{L} 2$ learners show greater sensitivity to antecedent and reflexive pronoun gender agreement than number agreement (Liu \& Nicol, 2010). Additionally, previous studies that are often cited to support the SSH (Papadopoulou \& Clashen, 2003) and also to discredit the SSH (Witzel et al., 2012) manipulated gender agreement in their test sentences as a cue to resolve temporary disambiguation. In an attempt to make comparability possible across these investigations, the same disambiguating information was employed in the present experiment. In this respect, the sentences of particular interest were as follows (constituents in boldface showing the direction of disambiguation):

High Attachment-Forced Condition

(1a) The brother of the girl who introduced himself at the party was very popular.

Low Attachment Forced Condition

(1b) The brother of the girl who introduced herself at the party was very popular.

The RC who introduced himself/herself in these sentences were placed in a structural position that would allow it to modify either NP (the brother or the girl) in the complex genitive NP (i.e. NP-of-NP). The proper target for the RC attachment was signaled by agreement between the antecedent and gender of the reflexive pronoun. To illustrate, while herself indicates low attachment to the corresponding NP the girl, himself indicates high attachment to the corresponding NP the brother. Consequently, twentyfour experimental test items were developed and balanced in a way that the reflexive pronouns (himself/herself) were evenly linked with each attachment type (twelve experimental items for high attachment as illustrated in (1a) above and twelve experimental items for low attachment preference as illustrated in (1b) above. In addition to the experimental items, twenty-four (24) unambiguous fillers were created to distract participants from the purposes of the experiment. In total, there were forty-eight (48) sentences in the present experiment. Simple comprehension checks in the form of YES / NO questions followed half of these items. Experimental test sentences and filler items were presented in a way that no more than two experimental items appeared successively.

In the test sentences, common nouns (with the article the) were used in all NPs forming the complex genitive NP constructions and the constituent nouns were connected with the preposition of. The 
complex NP which is modified by the $\mathrm{RC}$ was deliberately placed in the subject position unlike the previous studies which used test items constructed to include the complex NP as object of the main verb (e.g., Dussias, 2003; Felser et al., 2003; Fernandez, 2002, 2003; Frenck-Mestre, 1999, 2002; Papadopoulou \& Clahsen, 2003). This was done to downplay the possible confounding effects of the contextual information, which would otherwise precede the RC and possibly cause the readers to develop anticipations as to which noun in the complex NP to be modified by the RC. This kind of anticipations would interfere with the default tendency to attach the RC and undesirably affect the outcome of the study.

The rationale for designing the experimental test sentences was that if the parsing mechanism tends to systematically attach the RC to high NP (i.e., the brother in (1a) above), it will be forced to reanalyze when the fragment including the disambiguating information (i.e. who introduced herself,) is processed. As the reflexive pronoun herself refers to the female antecedent the girl, the reanalysis will require to change the attachment of the $\mathrm{RC}$ from the preferred $\mathrm{NP}_{1}$ (i.e., the brother) to the dispreferred $\mathrm{NP}_{2}$ (i.e., the girl). Since the reanalysis is thought to demand additional processing, the forced processing of the dispreferred attachment site (i.e., the girl) should take longer to read than a similar sentence including an ambiguity resolved in favor of high attachment (e.g., see (1a) above).

Five regions were identified as indicated in Table 1 below for the experimental test items. The third region where the RC was placed hosted the disambiguating information. For this reason it was assigned as the critical region. If the participants had a default low attachment preference, longer fixation durations in the third region would be expected in sentences where high attachment was forced. On the other hand, if they opted for high attachment, longer fixation durations in the third region would be expected in sentences, where low attachment was forced. The length of the experimental sentences and the words that appeared in each region were balanced for length across all experimental items.

Table 1. Identified Regions of the Target Experimental Items for RC Attachment

\begin{tabular}{ccccc}
\hline \multicolumn{5}{c}{ Regions } \\
\hline $\mathbf{1}$ & $\mathbf{2}$ & $\mathbf{3}$ & $\mathbf{4}$ & $\mathbf{5}$ \\
\hline The husband & $\begin{array}{c}\text { of the } \\
\text { woman }\end{array}$ & that blachment-Forced herself & $\begin{array}{c}\text { for the } \\
\text { breakup }\end{array}$ & $\begin{array}{c}\text { wanted a } \\
\text { divorce }\end{array}$ \\
\hline \multicolumn{5}{c}{ High Attachment-Forced } \\
\hline The son & of the queen & that devoted & to the & died very \\
& & himself & kingdom & young \\
\hline
\end{tabular}

\subsection{Data collection and analysis}

Eye movements of the participants were recorded using an eye tracking equipment with a sampling rate of $120 \mathrm{~Hz}$. The eye-tracking device was unobtrusively situated facing the participants below a 20" LED monitor with a resolution of $1600 \times 900$. The data was processed by using a software and exported from the device. The participants were seated about $60 \mathrm{~cm}$ away from the monitor. Instructions regarding the design of the experiment were provided in the participants' L1 Turkish. In order to calibrate the eyetracking device for the experimentation, the participants were asked to follow a fixation mark (a hashtag) which moved around the screen. After achieving an acceptable calibration, they did a practice session with a design which exactly matched that of the actual experimentation. Before the beginning of each trial, the fixation sign appeared at the center of the computer screen. Later, the test item followed the fixation sign on the same region. All test sentences were presented on the monitor as a single line of text 
with standard punctuation and capitalization. The participants' task was to read each sentence silently at their natural reading pace to make sure that they would correctly answer YES/NO questions which appeared occasionally on the screen after the test item disappeared. After participants finished reading the target sentence, they pressed the space key on the keyboard as instructed before and then the target sentence disappeared from the screen. When the target sentences were not followed by a YES/NO comprehension question, an arrow pointing right showed up on the screen, which signaled to continue with the next trial by pressing the space key again when ready. During the trials which did include a comprehension question, the participants' pressed the left arrow key on the keyboard for YES or the right arrow for $\mathrm{NO}$ and then automatically the next trial began.

For the data analysis, $20 \%$ error rate in the comprehension questions was the criterion for inclusion. However, no participant scored below the eighty percent accuracy rate. The following four eye-tracking measures were reported in the present study:

(1) Total sentence time: the total of all fixation durations for the whole sentence.

(2) Gaze duration: the total of the fixation durations in a region after first entering that region until leaving it.

(3) Go-past time: the fixation durations recorded during the time participants look at the target word (region) as well as any time spent rereading earlier regions of the sentence before going ahead to analyze new portions of the sentence.

(4) Total time in region: the total of all fixation durations per region.

\section{Results}

Mean scores for the measure of total sentence time in milliseconds (ms) and standard deviations for the processing of the experimental test items by the control group and L2 learner group appear in Table 2 below. This particular eye-tracking measure indicates an overall processing preference for the attachment of the RCs in the test sentences. The results for the control group from the analysis of variance (ANOVA) conducted with subject $(F 1)$ and with items $(F 2)$ as a random variable showed that there was a statistically significant difference between the total sentence time measures of low attachment-forced and high attachment-forced conditions, indicating elevated fixation durations for the high attachment sentences. $(F 1(1,22)=9.711, p<.004 ; F 2(1,22)=10.103, p<.015)$. This could be taken to mean that sentences that force attachment of RC to the high NP were read slower, implying a preference for low attachment by native English speakers. On the other hand, the results of the ANOVA for L2 learners demonstrated an attachment preference in the opposite direction of the native English speakers with significantly longer total sentence time measure for low attachment sentences $(F 1(1,24)$ $=11.204, p<.001 ; F 2(1,22)=12.871, p<.0025)$, which suggests that L2 learners took longer to process sentences that force disambiguation of the RC towards low NPs.

Table 2. Mean (standard deviations) total sentence time measure for the experimental test items

\begin{tabular}{lllll}
\hline & \multicolumn{4}{c}{ Participant Groups } \\
\hline & Native Speakers & \multicolumn{2}{c}{ L2 Learners } \\
\hline High & Low & High & Low \\
\hline Total sentence time & $\mathbf{3 8 5 3}$ & $\mathbf{3 6 9 3}$ & $\mathbf{4 7 9 5}$ & $\mathbf{5 1 4 4}$ \\
& $(749)$ & $(731)$ & $(751)$ & $(919)$ \\
\hline
\end{tabular}

Note: Boldface type indicates statistically significant difference between two measures. 
As for the analysis for the individual regions which were demonstrated above in Table 1, two ANOVAs with subject $(F 1)$ and with items $(F 2)$ as a random variable were run and the mean gaze duration, go-past time, total time in region measures were presented in Table 3 for native English speakers and Table 4 for L2 learners below.

Table 3. Mean fixation durations (standard deviations) of native English speakers in the regions

\begin{tabular}{|c|c|c|c|c|c|}
\hline & \multicolumn{4}{|c|}{ Regions } & \multirow[b]{2}{*}{5} \\
\hline & 1 & 2 & 3 & 4 & \\
\hline & \multicolumn{4}{|c|}{ Low Attachment } & \\
\hline & $\begin{array}{c}\text { The } \\
\text { husband }\end{array}$ & of the woman & $\begin{array}{l}\text { that blamed } \\
\text { herself }\end{array}$ & $\begin{array}{l}\text { for the } \\
\text { breakup }\end{array}$ & $\begin{array}{c}\text { wanted a } \\
\text { divorce }\end{array}$ \\
\hline & \multicolumn{4}{|c|}{ High Attachment } & \\
\hline & The son & of the queen & $\begin{array}{l}\text { that devoted } \\
\text { himself }\end{array}$ & $\begin{array}{c}\text { to the } \\
\text { kingdom }\end{array}$ & $\begin{array}{c}\text { died very } \\
\text { young }\end{array}$ \\
\hline \multicolumn{6}{|l|}{ Gaze Duration } \\
\hline Low Attachment & $321(77)$ & $433(104)$ & $729(148)$ & $466(115)$ & $660(189)$ \\
\hline High Attachment & $319(81)$ & $449(99)$ & $749(128)$ & $495(120)$ & $682(175)$ \\
\hline \multicolumn{6}{|l|}{ Go-past Time } \\
\hline Low Attachment & & $458(106)$ & $821(181)$ & $585(162)$ & $590(161)$ \\
\hline High Attachment & & $497(129)$ & $896(224)$ & $640(163)$ & $593(129)$ \\
\hline \multicolumn{6}{|l|}{ Total Time in Region } \\
\hline Low Attachment & $431(123)$ & $696(211)$ & $1089(303)$ & $678(241)$ & $799(214)$ \\
\hline High Attachment & $455(148)$ & $746(234)$ & $1180(375)$ & $703(174)$ & 759 (199) \\
\hline
\end{tabular}

Note: Boldface type indicates statistically significant difference between two measures.

Table 4. Mean fixation durations (standard deviations) of L2 learners in the regions

\begin{tabular}{|c|c|c|c|c|c|}
\hline & \multicolumn{4}{|c|}{ Region } & \multirow[b]{2}{*}{5} \\
\hline & 1 & 2 & 3 & 4 & \\
\hline & \multicolumn{4}{|c|}{ Low Attachment } & \\
\hline & $\begin{array}{c}\text { The } \\
\text { husband }\end{array}$ & of the woman & $\begin{array}{l}\text { that blamed } \\
\text { herself }\end{array}$ & $\begin{array}{l}\text { for the } \\
\text { breakup }\end{array}$ & $\begin{array}{l}\text { wanted a } \\
\text { divorce }\end{array}$ \\
\hline & \multicolumn{4}{|c|}{ High Attachment } & \\
\hline & The son & of the queen & $\begin{array}{l}\text { that devoted } \\
\text { himself }\end{array}$ & $\begin{array}{c}\text { to the } \\
\text { kingdom }\end{array}$ & $\begin{array}{l}\text { died very } \\
\text { young }\end{array}$ \\
\hline \multicolumn{6}{|l|}{ Gaze Duration } \\
\hline Low Attachment & $326(91)$ & $526(157)$ & $1165(242)$ & $659(121)$ & $833(199)$ \\
\hline High Attachment & $305(73)$ & $534(179)$ & $1087(221)$ & $634(131)$ & $882(217)$ \\
\hline \multicolumn{6}{|l|}{ Go-past Time } \\
\hline Low Attachment & & $562(176)$ & $1439(381)$ & $834(205)$ & $829(205)$ \\
\hline High Attachment & & $558(187)$ & $1351(357)$ & $799(163)$ & $851(177)$ \\
\hline \multicolumn{6}{|l|}{ Total Time in Region } \\
\hline Low Attachment & $539(183)$ & $883(271)$ & $1705(289)$ & $985(228)$ & $1032(238)$ \\
\hline High Attachment & $441(125)$ & $849(224)$ & $1486(253)$ & 863 (139) & $1156(234)$ \\
\hline
\end{tabular}

Note: Boldface type indicates statistically significant difference between two measures.

For the native speaker group, total time in the critical region, region 3, was statistically higher for high attachment-forced conditions than those for low attachment-forced conditions: $F 1(1,22)=5.412$, $p<.05, F 2(1,22)=6.109, p<.05$. This finding shows that when the RC modifier forcing attachment to the high $\mathrm{NP}\left(\mathrm{NP}_{1}\right)$ was encountered, it might have challenged the default processing tendency of native English speakers and caused them to reconsider their initial interpretation. This reconsideration might have led to the change of attachment of the RC from the preferred $\mathrm{NP}_{2}$ to the dispreferred $\mathrm{NP}_{1}$, which was reflected in the elevated fixation durations in the region. Another statistically significant 
difference was recorded in region 3 for go-past time measure again with sentences forcing high attachment read more slowly: $F 1(1,22)=6.821, p<.05, F 2(1,22)=5.902, p<.05$. This particular finding also suggests that when there is a mismatch between the default processing preference and the interpretation of the sentence, which seems to be the case in the high attachment-forced condition, they might have felt the need to go back and check again to see if there is a problem. Overall, the statistically longer fixation durations in the aforementioned regions in the native English speaker data complement the findings from total sentence time measure and suggest a clear processing preference for low $\mathrm{RC}$ attachment.

Similar to the results of total sentence time measure, which was the first indicative of a bias towards high attachment for L2 learner group, the findings of per region analyses illustrated in Table 4 above revealed an attachment tendency in the opposite direction of native English speakers. In region 3, total time measures were significantly longer for low attachment sentences than for high attachment sentences: $F 1(1,22)=10.679, p<.001, F 2(1,22)=8.841, p<.001$. Again, this might have been accounted for the reconsideration of L2 learners initial processing preferences when their default processing preference was challenged by the low attachment-forcing test items. Another interesting finding to note is that the sentences in which low attachment is forced had longer total time in region 1. This finding suggests that when there is an incompatibility with the high RC attachment, the L2 leaners took longer time to go back and check the head of the complex subject NP: $F 1(1,22)=7.774, p<.005$, $F 2(1,22)=4.319, p<.05$. The data from the go-past time measures indicates L2 learners' tendency to show regressive eye-movement patterns to overcome a processing difficulty in the particular region as significantly longer go-past time measures were recorded in Region 3 for low attachment-forced sentences: $F 1(1,22)=4.311, p<.05, F 2(1,22)=5.245, p<.05$. This suggests that the time taken to reread the critical region to resolve the processing difficulty was statistically longer for low-attaching sentences because of the likely mismatch between the default processing preference and what that particular region suggests. Overall, it can be concluded from these findings that the L2 learners showed a statistically reliable high attachment preference in sentences that include RC constructions in disambiguating structural positions.

\section{Discussion}

Based on the results reported above, it is obvious that the present experiment did not replicate the finding of the studies that have lent support for the SSH. In fact, the results of the present experiment have patterned like those of Witzel et al. (2012) in that the native English speakers and the L2 learner group displayed application of parsing strategies during the real-time comprehension of the test sentences including RC attachments, yet the type of the processing strategy applied was different for native English speakers and the L2 learner group. In line with the results of the studies on the processing of the RC attachments in L1 English (Carreiras \& Clifton, 1999; Frazier \& Clifton, 1996), the native English speakers showed a low attachment preference. This processing decision has been explained in regards to the structure-based universal parsing principle called Recency (Gibson et al., 1996), which guides the parsing mechanism to attach the incoming sentence constituents to the most recently processed elements. As for the Turkish learners of L2 English, they displayed a high attachment preference which was also consistent with their L1 processing decisions as it was revealed by a latest investigation (Uludag, 2020). This preference can been explained with regard to the structure-based universal parsing principle called Predicate Proximity (Gibson et al., 1996), which guides the processing mechanism to attach modifiers to argument positions. In fact, the findings of the present experiment demonstrated that the structure-based principles posited in the parsing of structurally ambiguous RCs were operative with native English speakers applying Recency and L2 learners applying Predicate 
Proximity. Therefore, the present experiment showed that the L2 learners employed in this study were capable of making use of structural information and applying structure-based processing principles in their real-time comprehension of temporarily ambiguous statements including English RC constructions.

It is possible to offer a number of potential interpretations as to why the direction of the attachment preferences on the target test items was different. First of all, a popular account that was also elaborated in the previous sections concerns the relative weighting of the structure-based processing principles of Recency and Predicate Proximity by native English speakers and by the L2 learners participated in this experiment. It is stated in the relevant literature that the strength of Predicate Proximity is determined by the average distance between the predicate heads (verbs) and their arguments and in languages that have comparably free word order like Turkish, this distance is fairly longer and greater initial activation of the predicate is necessary to facilitate attachment over greater distances. Therefore, Predicate Proximity outweighs Recency in such languages. On the other hand, the average distance between the predicate heads and their arguments are rather shorter in languages having a rigid word order formulation such as English, and thus Predicate Proximity is weaker. (Gibson et al., 1996). It is for this reason that a greater weight is assigned to Predicate Proximity in Turkish, and that the setting of this parameter in L1 Turkish might have affected the parsing of RCs in L2 by the Turkish participants.

Secondly, the difference in $\mathrm{RC}$ attachment preferences can be described with reference to the Tuning Hypothesis (Mitchell \& Cuetos, 1991). Essentially tuning hypothesis argues that the syntactic ambiguities are resolved in terms of the relative frequencies of previously encountered alternative disambiguations. To be more precise, the low attachment preference observed in the native English speakers may result from the prevalence of more low attachment resolutions in sentences including RCs and eventually being exposed to this sort of constructions. Similarly, the high attachment preference for Turkish learners of L2 English could be based on the prevalence of more high attachment resolutions in Turkish and the participants' exposure to these constructions. Put it differently, the L2 learners participated in this study might have been unable to get over their L1 tuning with this type of sentences.

Another consideration that could be offered to interpret the difference in the direction of the RC attachment preferences between the L2 English learners and native English speakers has to do with Implicit Prosody Hypothesis (Fodor, 1998). In this hypothesis it is claimed that a default prosodic contour is reflected on the stimulus even during silent reading and it could influence syntactic ambiguity resolution in a way that the processing mechanism opts for the structural analysis associated with the most natural (default) prosodic contour for the target structure. Specifically, in RC structures like the ones used in this study, the length of the RC might influence whether the reader will force a prosodic break between the RC and the complex genitive NP. Consequently, this influences the attachment preference with the assumption that low attachment is preferred if a break does not exist. Nevertheless, it should be noted that it is rather vague to determine the accuracy of this account without having L2 data from the production of the equivalent sentence types.

Finally, the different processing preferences displayed by the L1 English speakers and L2 English learners might be explained through the universal processing account, Construal Hypothesis (Frazier \& Clifton, 1996), which proposes to link the RC attachments to the higher NP. According to construal hypothesis, in languages that possesses two forms of genitive constructions (i.e., "NP of $N P$ " construction often called Norman genitive and " $s$ " possessive construction called Saxon genitive), low attachment $\left(\mathrm{NP}_{2}\right)$ is preferred over high attachment in Norman genitive constructions as the Saxon genitive construction could be alternatively used to modify the $\mathrm{NP}_{1}$ (as in the author's father was at the café). As a result, the processing mechanism applies the Grice's Maxim of Avoid Ambiguity and assumes that if high attachment were aimed, the Saxon genitive construction would have been used. In the light of this explanation, it could be argued that if the Turkish learners of L2 English failed to process 
the pragmatic implications of the Norman genitive, which does not exist in their L1, they would have simply referred to the default interpretation under the Construal Hypothesis by attaching the RC modifier to the higher NP with the target test items.

When the individual measures of data is analyzed in detail (i.e. per region analysis), the most important finding appears to be that Turkish learners of L2 English and native English speakers showed differences in total time at the critical region that hosted the RC. This was the main indicator of a high attachment preference for the L2 learners and a low attachment preference for native English speakers. Especially the difference in the go-past time measure in the critical region clearly reveals the need for the participants to go back and check the head of the complex subject NP when there is an incompatibility with their preferred attachment tendency and the target test item forcing the attachment to the opposite direction. Compared to the inconclusive results in the literature of the L2 sentence processing for the RC modifiers, especially those taken to support the SSH by not being able to get comparable differences (Felser et al., 2003; Papadopolou \& Clahsen, 2003) these findings are particularly intriguing. In this respect, it can be argued that task sensitivity might have played a role in the difference. It is noteworthy that all studies that failed to detect an attachment preference in L2 RC attachment ambiguities employed a self-paced reading tasks (Dussias, 2003; Felser et al., 2003; Fernandez, 2003; Papadopoulou \& Clahsen, 2003), yet those few studies having displayed attachment preferences adopted the eye-tracking methodology (Frenck-Mestre, 1999, 2002; Witzel et al., 2012). As it is argued above, the use of a potentially sensitive methodology such as eye-tracking might have helped to unravel this often subtle difference in the RC attachment preferences.

A final consideration to offer explanation for the present findings is that the position of the complex NP in the present experiment might have better facilitated the detection of the processing preference as argued in the Materials section. The possible confounding effect of the contextual information might have been diminished by the position of the RC modifier and this might have withheld the participants from developing contextual anticipations as to which noun in the complex NP is more likely to be modified by the RC attachment. Furthermore, previous real-time reading studies on the stimulus test sentences have found wrap-up effects, namely, longer fixation durations on the last constituent of the sentences (Rayner, Kambe \& Duffy, 2000), therefore, eliminating this confounding effect by not situating the disambiguating $\mathrm{RC}$ as the final constituent of the sentence could have contributed to the present findings. Taking all into consideration, it can be suggested that the test sentences developed for the present study might warrant a more effective investigation of whether L2 learners are able to create and utilize abstract syntactic representations through the application of structure-based processing principles.

\section{Conclusion}

The purpose of the present study was to acquire a better understanding of the nature of real-time L2 sentence processing by examining the attachment preferences of Turkish learners of L2 English and native English speakers for RC attachment ambiguities. The results suggest evidence that L2 sentence processing decisions are not made randomly as the participants' processing preferences under the conditions of the present study appeared to be systematically driven by structure-based parsing principles. In this respect, the results of the present study can be taken to pose a challenge for the assumptions of the SSH. According to the SSH (Clahsen \& Felser, 2006a, p.117), it is argued that irrespective of their function in guiding L1 sentence comprehension, universal parsing principles such as minimal attachment or late closure do not govern real-time L2 sentence processing. More specifically, it is suggested that "the L2 parser will be unable to successfully apply even universal processing 
mechanisms if the L2 grammar fails to provide sufficient grammatical information" (Clahsen \& Felser, 2006a, p.120). Nonetheless, the present study has shown that a universal parsing mechanism could be operative during L2 sentence comprehension. An equally important claim of SSH concerns the consideration that L2 learners do not rely on syntactic or structure-based parsing principles to the same extent as native speakers because the syntactic representations formed by L2 learners to interpret L2 input data are shallower and less detailed than those of native speakers. For this reason, L2 learners should demonstrate no particular parsing strategy or bias based on syntactic representations they make and, instead their processing decisions are made randomly when the nonstructural cues such as lexicalsemantic, pragmatic, discourse information are unavailable. These claims, however, were challenged by the results from the present ambiguity resolution tasks, in which the L2 learners showed statistically significant attachment preferences. While it is likely to explain part of the results by assuming a role for lexical, semantic, pragmatic or plausibility information, it would be challenging to explain the entire pattern of results without addressing the role of structure-based parsing principles. If these principles are interpreted to indicate rich syntactic processing, it seems that native speakers and L2 learners are able to perform hierarchically deep and detailed syntactic processing of structures during real-time sentence comprehension. In the present study, the realization of rich syntactic processing is highlighted by the general fixation patterns in the on-line eye-tracking task. It is necessary to emphasize that eyetracking seems to be the suitable means that could yield precise indications of moment-by-moment syntactic computations performed by L2 learners. For this reason, it is considered as the appropriate methodology that fits well into the investigation of real-time sentence processing.

\section{Ethics Committee Approval}

The author(s) confirm(s) that the study does not need ethics committee approval according to the research integrity rules in their country (Date of Confirmation: August 18, 2020).

\section{References}

Brysbaert, M. \& Mitchell, D. C. (1996). Modifier attachment in sentence processing: Evidence from Dutch. Quarterly Journal of Experimental Psychology, 49(A), 664-695.

Carreiras, M. \& Clifton, C. Jr. (1999). Another word on parsing relative clauses: Eyetracking evidence from Spanish and English. Memory \& Cognition, 27, 826-833.

Clahsen, H. \& Felser, C. (2006a). Grammatical processing in language learners. Applied Psycholinguistics, 27, 3-42.

Clahsen, H. \& Felser, C. (2006b). Continuity and shallow structures in language processing. Applied Psycholinguistics, 27, 107-126.

Clahsen, H. \& Felser, C. (2006c). How native-like is non-native language processing? Trends in Cognitive Sciences, 10, 564-570.

Clahsen, H. \& Felser, C. (2017). Some notes on the shallow structure hypothesis. Studies in Second Language Acquisition, 40(3), 693-706.

Cuetos, F., Mitchell, D. C., \& Corley, M. M. B. (1996). Parsing in different languages. In M. Carreiras, J. E. García-Albea, \& N. Sebastián-Gallés (Eds.), Language processing in Spanish (145-187). Hillsdale, NJ, US: Lawrence Erlbaum Associates, Inc. 
Dinctopal-Deniz, N. (2010). Relative clause attachment preferences of Turkish L2 speakers of English. In B. VanPatten \& J. Jegerski (Eds), Research in second language processing and parsing (27-63). Amsterdam: John Benjamins Publishing Company.

Dussias, P. (2003). Syntactic ambiguity resolution in L2 learners. Studies in Second Language Acquisition, 25, 529-557.

Felser, C., Roberts, L., Marinis, T. \& Gross, R. (2003). The processing of ambiguous sentences by first and second language learners of English. Applied Psycholinguistics, 24, 453-489.

Felser, C. \& Roberts, L. (2007). Processing wh-dependencies in a second language: A cross-modal priming study. Second Language Research, 23(1), 9-36.

Fernandez, E. (2002). Relative clause attachment in bilinguals and monolinguals. In R. Heredia \& J. Altarriba (Eds.), Bilingual sentence processing (187-215). Amsterdam: Elsevier.

Fernandez, E. (2003). Bilingual sentence processing. Amsterdam: John Benjamins.

Fodor, J. D. (1998). Learning to parse? Journal of Psycholinguistic Research, 27, 285-317.

Frazier, L. (1979). On comprehending sentences: Syntactic parsing strategies. Storrs, CT: University of Connecticut dissertation.

Frazier, L. \& Clifton, C. Jr. (1996). Construal. Cambridge, MA: MIT Press.

Frenck-Mestre, C. (1999). Examining second language reading: An on-line look. In A. Sorace, C. Heycock \& R. Shillcock (Eds.), Language acquisition: Knowledge representation and processing (474-478). Amsterdam: North-Holland.

Frenck-Mestre, C. (2002). An on-line look at sentence processing in the second language. In R. Heredia \& J. Altarriba (Eds.), Bilingual sentence processing (217-236). Amsterdam: Elsevier.

Gibson, E., Pearlmutter, N., Canseco-Gonzalez, E. \& Hickok, G. (1996). Recency preference in the human sentence processing mechanism. Cognition, 59, 23-59.

Gorrell, P. (1995). Syntax and Parsing. Cambridge, UK: Cambridge University Press

Kirkici, B. (2004). The processing of relative clause attachment ambiguities in Turkish. Turkic Languages, 8, 111-121.

Liu, R. \& Nicol, J. (2010). Online processing of anaphora by advanced English learners. In M. T. Prior, Y. Watanabe and S. Lee (Eds.), Selected proceedings of the 2008 Second Language Research Forum (150-165). Somerville, MA: Cascadilla Proceedings Project.

Mitchell, D. \& Cuetos, F. (1991). The origins of parsing strategies. In C. Smith (Ed.), Current Issues in Natural Language Processing (1-12). Center for Cognitive Science, University of Austin.

Papadopoulou, D. (2006). Cross-linguistic variation in sentence processing. Evidence from RC attachment preferences in Greek. Dordrecht, the Netherlands: Springer

Papadopoulou, D. \& Clahsen, H. (2003). Parsing strategies in L1 and L2 sentence processing. Studies in Second Language Acquisition, 25, 501-528.

Rayner, K., Kambe, G, \& Duffy, S. A. (2000). The effect of clause wrap-up on eye movements during reading. Quarterly Journal of Experimental Psychology, 53(A), 1061-1080.

Roberts, L. (2010). Parsing the L2 input, an overview: Investigating L2 learners' processing of syntactic ambiguities and dependencies in real-time comprehension. Language, interaction and acquisition, l(2), 189-205. 
Uludag, O. (2020). Transfer of L1 processing strategies to the interpretation of sentence-level L2 input: A cross-linguistic comparison on the resolution of relative clause attachment ambiguities. Eurasian Journal of Applied Linguistics, 6(2), 155-188.

VanPatten, B. \& Jegerski, J. (2010). Second language processing and parsing: The issues. In B. VanPatten and J. Jigerski (Eds.), Research in second language processing and parsing (3-24). Philadelphia, PA: John Benjamins Publishing Co.

VanPatten, B. \& Williams, J. (2007). Introduction: The nature of theories. In B. VanPatten and J. Williams (Eds.), Theories in second language acquisition: An introduction (1-16). Mahwah, NJ: Lawrence Erlbaum.

Witzel, J., Witzel, N. \& Nicol, J. (2012). Deeper than shallow: Evidence for structure-based parsing biases in second-language sentence processing. Applied Psycholinguistics, 33, 419-456.

\section{Appendix A. Experimental items for $\mathrm{RC}$ attachment ambiguity resolution}

\section{Low Attachment Forced}

1. The father of the girl that taught herself advance mathematics felt very proud.

2. The son of the actress that fooled herself in front of cameras blushed with shame.

3. The wife of the actor that shot himself on the set suffered from depression.

4. The husband of the woman that blamed herself for the breakup wanted a divorce.

5. The nephew of the maid that cut herself with the knife called the ambulance.

6. The brother of the waitress that improved herself in business opened a restaurant.

7. The boyfriend of the bridesmaid that undressed herself in public had much alcohol.

8. The daughter of the salesman that praised himself all the time was very rude.

9. The aunt of the schoolboy that found himself in trouble phoned the police.

10. The girlfriend of the waiter that criticized himself too often had no self-confidence.

11. The mistress of the man that enjoyed himself at the bar was very intelligent.

12. The daughter of the headmaster that hated himself for failing always seemed unhappy.

\section{High Attachment Forced}

1. The son of the queen that devoted himself to the kingdom died very young.

2. The brother of the waitress that burned himself at the café was usually careless.

3. The uncle of the schoolgirl that prepared himself for the race was a great athlete.

4. The father of the bride that embarrassed himself at the wedding felt humiliated.

5. The husband of the woman that trained himself to cook surprised family members.

6. The grandfather of the girl that hurt himself at home shocked whole family.

7. The mother of the boy that complimented herself in public looked very elegant.

8. The daughter of the actor that introduced herself in the party was very popular.

9. The sister of the schoolboy that dressed herself nicely attracted much attention.

10. The aunt of the businessman that killed herself at home was in much debt.

11. The grandmother of the groom that injured herself at wedding worried the guests.

12. The wife of the man that bought herself diamond ring caused financial trouble. 


\section{İkinci dilin gerçek zamanlı olarak işlemlenmesi sırasında tümcebilimsel çözümleme stratejilerinin kullanımı}

\section{$\ddot{O} \mathbf{z}$}

$\mathrm{Bu}$ çalışmanın amacı sözdizimsel belirsizlikleri içeren cümle oluşumlarının gerçek zamanlı olarak ikinci dil öğrenenler tarafından işlemlenmesi sırasında tümcesel çözümleme stratejilerinin kullanılıp kullanılmadığını araştırmayı amaçlamaktadır. Bu maksatla, sıfat cümleciği belirsizliklerini içeren cümle yapılarının İngilizce öğrenen Türk öğrenciler ve ana dili İngilizce olan kontrol grubundaki denekler tarafindan okunup işlemlenmesi sırasında kayıt edilen göz hareketleri incelenmiştir. Sonuçlar hem ana dilde ve hem de ikinci dilde elde edilen işlemleme kararlarının sistematik bir şekilde tümcebilimsel çözümleme stratejileri tarafından yönlendririldiğini ve işlemleme kararlarının anlambilimsel, edimsel ya da diğer yapı tabanlı olmayan bilgi kaynaklarına dayanılarak rastlantısal bir şekilde elde edilmediğini göstermektedir. Bu sonuçlar, ikinci dil öğrenenlerin de ana dili İngilizce olan deneklerin gerçek zamanlı olarak İngilizce cümleleri işlemlemeleri sırasında oluşturdukları soyut, hiyerarşik olarak derin ve detaylı tümcebilimsel simgelere benzer simgeleri oluşturup kullanabildiklerini önermektedir.

Anahtar sözcükler: cümle işlemleme; tümcebilimsel çözümleme; belirsizlik çözümleme; göz izleme; eklenti

\section{AUTHOR BIODATA}

Onur Uludağ works as a language instructor and the deputy director of the School of Foreign Languages at Yildiz Technical University, Istanbul. He received his M.A. degree in Applied Linguistics at Texas Tech University in 2012 and earned his Ph.D. in English Language Education at Cukurova University in 2018. His research interests include instructed second language acquisition, psycholinguistics, input processing and second language vocabulary acquisition. 